\title{
EDUCAÇÃO E NOVAS TECNOLOGIAS
}

\author{
Ramón Peña Castro*
}

MY

ovas Tecnologias, Produtividade, Competitividade... são algumas das palavras mais repetidas por empresários e tecnocratas com a finalidade de tornar accitáveis as políticas de "ajuste", supostamente destinadas a criar condições para a "retomada do crescimento",

É visivelmente enganosa a idćia de que a modernização tecnológica e gerencial das empresas - que até agora só tem levado ao aumento do desemprego - beneficie aos trabalhadores ou, como diz o discurso oficial, "a sociedade como um todo".

Diversas pesquisas demonstram ${ }^{1}$ que na indústria automobilística brasilcira, (setor mais representativo das tecnologias modernas) a introdução de novas tecnologias dá-se de forma unilateral e limitada, servindo principalmente para reduzir o emprego global, para reforçar a organização fordista do trabalho ${ }^{2}$.

Isso acontece porque o objetivo central das mudanças tecno-organizacionais consiste em elevar a produtividade do trabalho, mediante o reforçamento do seu controle e da sua intensificação.

O neoliberalismo - nova fantasia do capitalismo - identifica a tecnologia com a noção religiosa do bem absoluto, para incutir a idéia de que tanto os indivíduos como as instituições públicas (entre as quais a Escola) devem curvar-se ao suposto imperativo tecnológico, cabendo à escola atender, prioritariamente, às demandas do mercado de trabalho.

De acordo com este raciocínio, o atual sistema de ensino, bastante precário, deve ser reconstruído para formar um novo tipo de supertrabalhador, que as empresas precisam para realizar as potencialidades contidas nas novas tecnologias. A escola ideal - segundo a visão empresarial - deveria servir para formar um operário polivalente, que trabalhe por vários e receba por um, que desempenhe múltiplas funções, conheça tudo no seu setor, possua noções de matemática e estatística, saiba reagir a imprevistos, interagir em grupo e responder pela qualidade total da produção.

Com a vista voltada para csse ideal de superoperário, o empresariado preconiza hoje uma dupla flexibilização ou liberalização: do mercado de trabalho, por um lado, e do sistema de ensino, por outro.

Q u a n t o à flexibilização do mercado de trabalho. os resultados são muito eloquentes: fim da estabilidade, arrocho salarial e questionamento dos direitos trabaIhistas. Quanto à flexibilização do sistema de ensino, as suas manifestações concretas são o avanço da privatização (na forma de empresa-

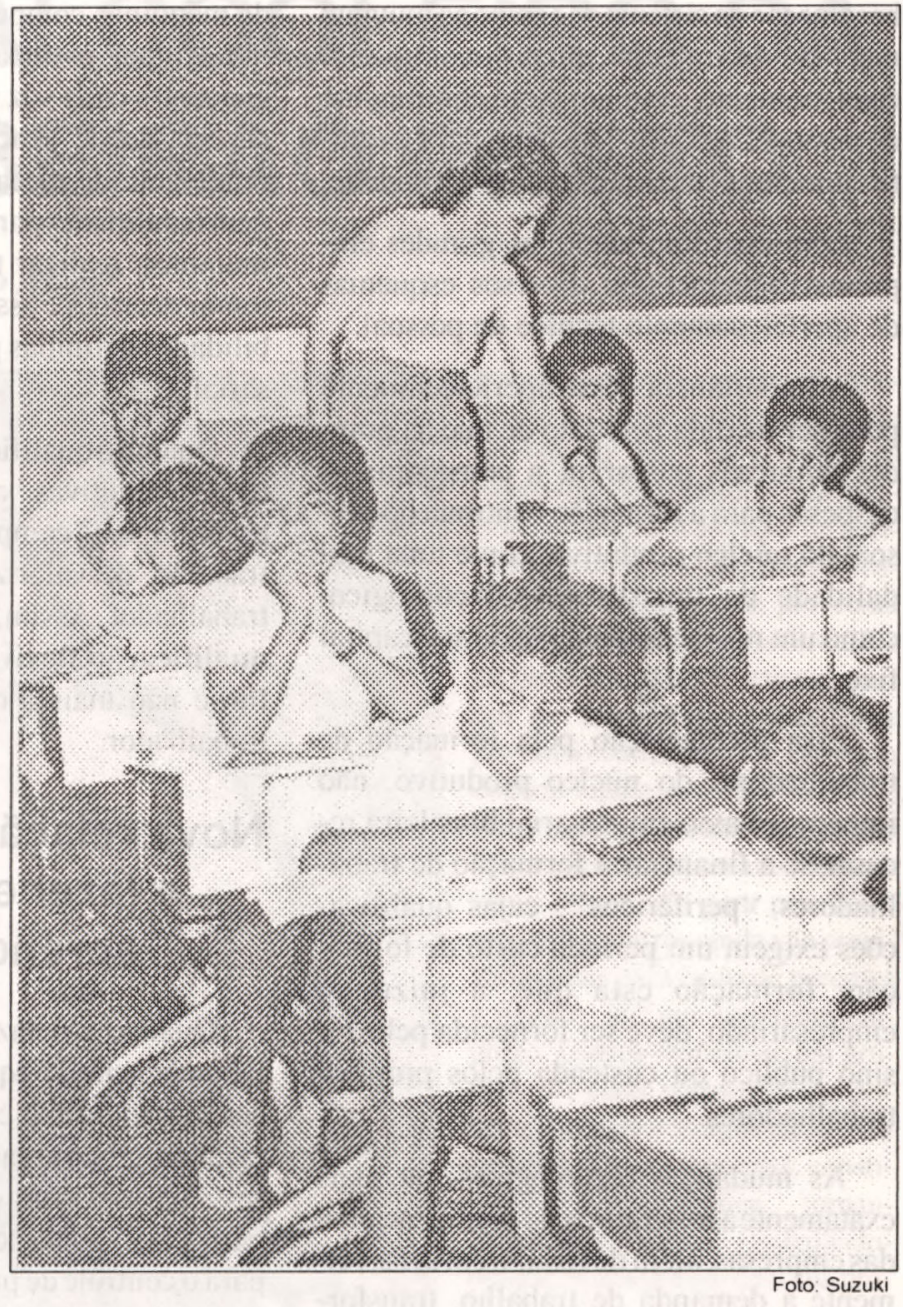
escola e de subsídios públicos a escolas privadas) e a subdivisão crescente do sistema de ensino em duas partes cada vez mais diferenciadas. Uma, formada por escolas públicas e privadas de primeira classe, destinadas à formação das elites cientificotécnicas e trabalhadores do "núcleo" produtivo; outra, representada por escolas de segunda classe, destinadas à cducação dos trabalhadores das " periferias" do sistema produtivo e dos serviços subalternos.

A indicada tendência segregacionista do sistema de ensino guarda estreita correlação com o dualismo da estratćgia econômica do capitalismo brasileiro, que combina trabalho barato e fordismo de segunda classe com introdução, lenta e seletiva, de tecnologias de automação para melhorar a compctitividade dos produtos.

Resulta claro que a proposta educaciodiscriminatória dos trabalhadores. A primeira classe. formada por trabalhadores do núcleo do sistema produtivo que respondem pela manutenção, preparação de equipamentos, controle de insumos e monitoramento de processos. A segunda classe, formada por trabalhadores periféricos,que ocupam os postos menos valorizados e de mais fácil substituição, graças a supcroferta de mão-de-obra com menor qualificação. nal do empresariado implica uma divisão 
Cabe notar que as mudanças tecnológicas, especialmente quando são lentas e seletivas como no Brasil, não são o único ou principal fator determinante do perfil exigido da Escola. O empresariado, ao mesmo tempo que postula, como princípio político geral, a mais completa subordinação do sistema de ensinoao mutante mercado de trabalho, precisa contar, $\mathrm{em}$ cada momento, com um certo contingente de pessoal especializado, apto para garantir aumentos imediatos da produtividade.

Com essa finalidade, as grandes empresas implementam diversos esquemas de aperfeiçoamento técnico de pessoal.

A importância desse aperfeiçoamento pode ser medida pelo fato de que as grandes empresas passaram a considerar as despesas para a formação contínua do pessoal do núcleo produtivo, como uma modalidade de investimento tecnológico, como um novo componente do seu capital fixo.

Essa preocupação pcla formação de trabalhadores do núcleo produtivo, não impede a classe empresarial brasileira recusar-se a financiar a formação de trabalhadores "periféricos", cujas qualificações exigem um período curto de formação, formação esta que, a juízo do empresariado, deve ser fornecida pclo ensino público ou custeada pelos próprios trabalhadores.

As mudanças tecnológicas, ou mais exatamente reestruturação organizacional das empresas, além de reduzirem sensivelmente a demanda de trabalho, transformam o seu conteúdo, assim como as qualificações exigidas pelos novos postos de trabalho, o que representa, como veremos a seguir, um desafio adicional para o sistema de ensino.

\section{Mudanças no conteúdo do trabalho e na qualificação}

A introdução de equipamentos automáticos e programáveis, além de reduzir a demanda de trabalho vivo (número de trabalhadores ocupados), reduz também o espaço e o tipo de intervenção humana no processo de produção.
Como resultado disso, muda o próprio conteúdo do trabalho vivo. Novas funções scnsitivas e cercbrais, relacionadas com o funcionamento da máquina de trabalho, com a concepção, processamento e controle do produto, são transformadas em programas codificados, em saber-fazer morto de máquinas computadorizadas. Ao mesmo tempo, o trabalho vivo residual se concentra cada vez mais em atividades de supcrvisão de processos programados e regulagem de mecanismos, as quais exi$\mathrm{gem}$ habilidades para operar $\mathrm{em}$ ambientes mutantes, realizar tarefas não-rotinciras, tomar decisõcs e assumir outras responsabilidades definidas pela estratégia empresarial.

Quanto à qualificação, as novas formas tecno-produtivas, ao possibilitarem um domínio mais completo do capital sobre o trabalho, desvalorizam a qualificação do trabalhador. Assim, o que passa a valer ć a qualificação flexível do posto de trabaIho c não mais a qualificação rígida do trabalhador.

\section{Nova relação entre saber e fazer e modo de aprendizagem}

Quando o "fazer" passa a ser uma incumbência de equipamentos automáticos, desaparece o espaço para "aprender fazendo". Neste caso, o trabalho vivo que resta passa a estar cada vez mais voltado para a interpretação de sinais codificados, para o controle de processos, desaparecendo o contato dircto (sensorial) com instrumentos ou produtos concretos. Em tais condições, a aprendizagem não depende tanto da experiência sensorial-motora (braços, pernas, tato, vistas, ouvidos, olfato), quanto da comprecnsão de linguagens simbólicas, da posse de capacidades para visualizar processos, verbalizar indicadores e interagir $\mathrm{cm}$ grupo.

Esses tipos de capacidades não são um subproduto da experiência empírica, própria do trabalho tradicional, são, pelo contrário, pré-requisitos para o trabalho automatizado. Esta mudança no tipo de atividade autoriza a falar de uma certa inversão na relação entre saber e fazer ou entre trabalho e aprendizagem. Antes, o saber era uma subproduto do fazer; agora. o saber é uma pré-condição para um fazer diferente.

Em decorrência do anterior temos uma tendência para a crescente separação (no tempo e no espaço) entre aprender e fazer, tendência essa que enfatiza o papel da atividade pedagógica.

Os novos fenômenos indicados acima tornam ainda mais urgente a necessidade social e política de reverter o processo de degradação do sistema nacional de ensino que, como é notório, reflete uma degradação mais geral, da política. da economia, da cultura, da vida coletiva $\mathrm{c}$ do meio ambiente.

Contra o pessimismo, que não pode deixar de suscitar a atual crise da Escola e da sociedade. só cabe apelar para a vontade humana de viver condignamente.

Cada dia um maior número de pessoas concorda com a idéia de que a reconstrução do sistema de ensino é tão urgente e relevante como acabar com a fome. Reconstruir o ensino, para torná-lo rcalmentc público, implica oferecer ao trabalhador a possibilidade de vir a ser algo mais que mercadoria força de trabalho. Para tanto, além de qualificar adequadamente para o trabalho moderno (e não necessariamente mercantil), a Escola, quando sacudida por um clã de solidariedade colctiva, semelhante ao da campanha cívica contra a fome, poderá se transformar $\mathrm{cm}$ instrumento fundamental de socialização humana. Só então farão sentido asbelas palavras de justiça social e cidadania.

\footnotetext{
* Ramón Peña Castro é Doutor em Economia e Prof. do Dpto. de Ciência Sociais e do Programa de Pós-Graduação em Educação da Universidade Federal de Saio Carlos (SP).

\section{NOTAS}

(1)CARVALHOR. deQ.eSCHMITZ. O fordismo está vivo no Brasil. In Novos Estudos CEBRAP, n.27, julho 1990, pp.148-156.

(2) Organização fordista do trabalhoé sinônimo de trabalho em cadeia, trabalho ritmado pela máquina, redução ao minimo da necessidade de pensar e separação radical entre fazer e saber para permitir o total controle mecânico do trabaIhador e a exploraçăo intensiva da sua força de trabalho.
} 